\title{
Ongoing rubella outbreak among adolescents in Salaj, Romania, September 2011-January 2012
}

D Janta (denisa.janta@insp.gov.ro) ${ }^{1,2}$, A Stanescu $^{1}$, E Lupulescu³, G Molnar , A Pistol $^{1}$

1. National Institute of Public Health, National Centre for Communicable Diseases Surveillance and Control, Bucharest, Romania

2. European Programme for Intervention Epidemiology Training (EPIET), European Centre for Disease Prevention and Control $(E C D C)$, Stockholm, Sweden

3. National Institute of Research and Development for Microbiology and Immunology 'Cantacuzino' - Reference Laboratory for Measles and Rubella, Bucharest, Romania

4. Ministry of Health, Bucharest, Romania

A rubella outbreak has been ongoing in Salaj, Romania since September 2011 involving 1,840 probable and confirmed cases among mainly unvaccinated adolescents. The index case had onset of illness on 6 September 2011. The highest number of cases was recorded among 10-14-year-olds and 15-19-year-olds. Complications were recorded for 11 cases and included meningitis and arthritis. Although the peak has passed, surveillance is being maintained in the region.

An outbreak of rubella with more than 1,800 cases was identified in Salaj, north-western Romania, a district with 241,014 inhabitants according to 2010 data (Figure 1).

The European Union (EU) case definition [1] was used in the outbreak investigation and of the 1,873 possible cases, 69 (3.6\%) were classified as laboratory-confirmed, 1,771 (94.6\%) as probable, defined according to clinical criteria and epidemiological links with a

\section{FIGURE 1}

District of Salaj, Romania

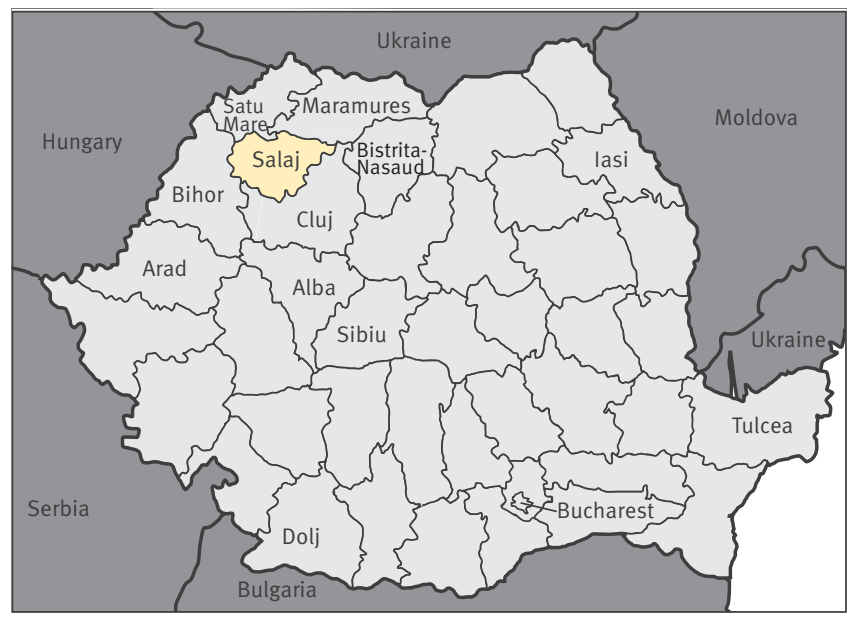

confirmed case, and 33 (1.8\%) were discarded. Of the 69 laboratory-confirmed cases, two were pregnant women but no case of congenital rubella infection (CRI) has been reported so far.

\section{Background}

Rubella is a statutorily notifiable disease in Romania since 1978 [2]. Until 2010, data were reported in aggregated format by age group. In 2010, a case-based reporting with mandatory laboratory confirmation was introduced.

Since December 2002, as part of the measles surveillance system, clusters of febrile rash are investigated by the local public health authorities and, in order to confirm the clinical diagnosis, it is recommended to take samples from five to ten cases in each cluster for serological testing for measles and, if the results are negative, for rubella. If rubella transmission is confirmed, pregnant women who are epidemiologically linked to a laboratory-confirmed case or who meet the clinical criteria are given priority for testing and are informed about the potential risks of congenital rubella syndrome (CRS) to the foetus. Although rubella is usually a mild febrile rash illness, infection during pregnancy can lead to miscarriage, stillbirth, and birth defects associated with CRS such as heart disease, blindness, deafness and mental retardation.

A national surveillance system for CRS was initiated in Romania in 2000. Newborns of rubella positive mothers have a rubella-specific IgM blood test tested for CRI and are reported in the CRI/CRS surveillance system according to the methodology in place [3].

Rubella is a vaccine preventable disease targeted for elimination in the WHO European Region by 2015 along with measles. Countries in the region have also committed to the prevention of CRS by the same year [4]. 
A rubella-containing vaccine was first available in Romania in 1998 (bivalent measles-rubella) and it was offered to girls aged between 15 and 18 years (birth cohorts 1980-1983) as part of a mass vaccination campaign following a nation-wide measles outbreak [5]. After a large rubella outbreak in 2002 to 2003, a rubella-containing vaccine was offered to girls aged between 13 and 14 years until 2008 (birth cohort 1994). In 2004, the measles-mumps-rubella (MMR) vaccine was introduced in the national immunisation schedule for children aged 12-15 months. Since 2004, MMR vaccination has also been offered to children aged seven years.

In 2002 to 2003, a large rubella outbreak occurred in Romania, with more than 115,000 cases reported nationwide and the highest incidence was reported in children of school age (2,564 per 100,000 population aged 5-9 years and 2,446 per 100,000 population aged 10-14 years [6]. By 2010, rubella incidence dropped to 1.6 per 100,000 population (2009: 2.9/100,000; 2008: $8.1 / 100,000)[7,8]$.

\section{Outbreak description}

The index case (laboratory-confirmed) was reported on 6 September 2011 to Salaj Public Health Authority in an unvaccinated 16-year-old student attending a local high school. Between 1 September 2011 and 23 January 2012, 1,840 confirmed and probable rubella cases were reported by Salaj Public Health Authority (Figure 2).

Of the 1,840 cases 1,069 were male and 771 were female, showing a male:female ratio of $1.4: 1$. The highest number of cases was recorded in people aged between10 and 19 years $(n=1,693)$. Of these, 1,206 cases were registered among 15-19-year-olds (58.6\% male and $41.4 \%$ female) with a male:female ratio of 1.4:1. The rest of 487 cases were registered among 10-14-year-olds ( $55.4 \%$ male and $44.6 \%$ female) with a male:female ratio of $1.2: 1$.Taking into account the fertile age, we registered 1,341 cases in people aged between 15 and 44 years with a male:female ratio of 1.3:1. Among these 1,341 cases $59.1 \%$ were male and $40.9 \%$ were female giving a male:female ratio of 1.3:1. Of all outbreak cases $23.3 \%(428 / 1,840)$ were registered among children born in 1996.

The incidence of rubella in Salaj was 763 per 100,000 population with the highest incidence among high school teenagers aged between 15 and 19 years $(9,555$ per 100,000 population for males and 7,067 for females) followed by 10-14 year-olds (3,854 per 100,000 population for males, 3,281 per 100,000 population for females).The third most affected age group was the age group of 20-24 year-olds with an incidence of 647 per 100,000 population among males and 154 per 100,000 population among females (Table).

Complications included meningitis ( $n=2$ cases) and arthritis ( $n=9$ cases). Thirty-five cases required hospitalisation and the median length of hospital stay was four days (minimum 1, maximum 9).

A total of 98 samples were tested for rubella IgM antibodies and 69 of these were confirmed as positive.

\section{FIGURE 2}

Distribution of probable and confirmed rubella cases by date of symptom onset, Salaj, Romania, 1 September 2011-23 January $2012(n=1,840)$

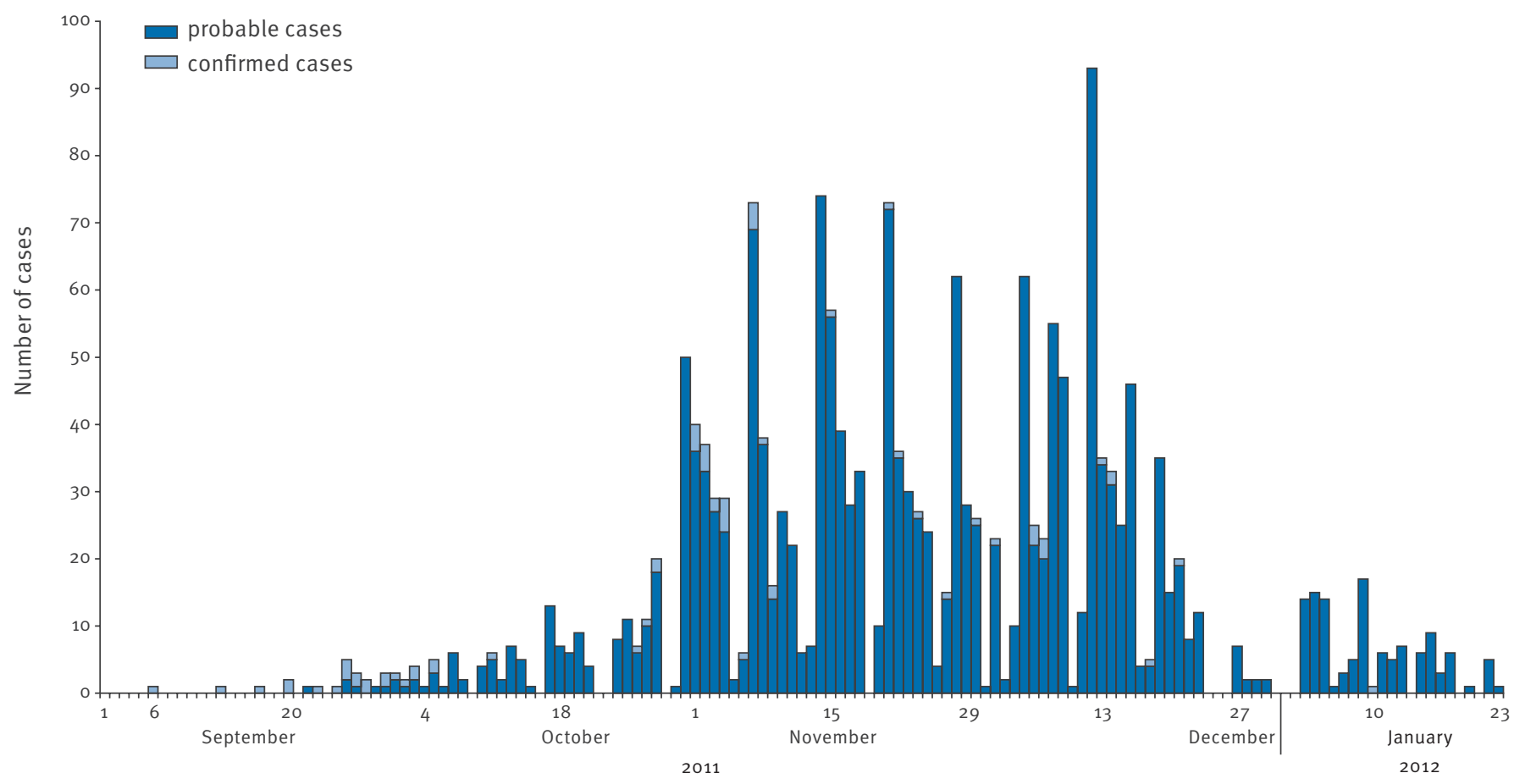


In clinical specimens from two cases rubella virus genotype $2 \mathrm{~B}$ was identified.

Vaccination coverage among the reported cases was low: $38(2.1 \%)$ of the total number of cases were vaccinated with one dose of rubella-containing vaccine. Taking into account the eligible birth cohorts for vaccination against rubella and the number of rubella cases reported during the outbreak, we calculated the proportion of rubella cases occurring in birth cohorts from 1989 to 2002. The highest proportion of cases was registered among people born from 1994 to 1997 (Figure 3).

We looked at the rubella vaccination coverage for Romania and Salaj district in the eligible birth cohorts for MMR vaccination at 12-15 months (birth cohort 2004-2008), for MMR vaccination at seven years (birth cohort 1998-2002) and the rubella dose administered only to girls in birth cohort 1989-2003. The rubella vaccination coverage of the 13 to 14 year-old females in

\section{TABLE}

Number of probable and confirmed cases $(n=1,840)$ and incidence of rubella by sex and age group, Salaj, Romania, 1 September 2011-23 January 2012

\begin{tabular}{|l|c|c|c|c|}
\hline \multirow{2}{*}{$\begin{array}{l}\text { Age group } \\
\text { (years) }\end{array}$} & \multicolumn{2}{|c|}{ Male } & \multicolumn{2}{c|}{ Female } \\
\cline { 2 - 5 } of cases & $\begin{array}{c}\text { Incidence } \\
\text { per } 100,000 \\
\text { population }\end{array}$ & $\begin{array}{c}\text { Number } \\
\text { of cases }\end{array}$ & $\begin{array}{c}\text { Incidence } \\
\text { per 100,000 } \\
\text { population }\end{array}$ \\
\hline $0-4$ & 4 & 62 & 4 & 64 \\
\hline $5-9$ & 3 & 46 & 2 & 31 \\
\hline $10-14$ & 270 & 3,854 & 217 & 3,281 \\
\hline $15-19$ & 707 & 9,555 & 499 & 7,067 \\
\hline $20-24$ & 64 & 647 & 14 & 154 \\
\hline $25-29$ & 10 & 112 & 3 & 36 \\
\hline $30-34$ & 4 & 42 & 12 & 139 \\
\hline $35-39$ & 4 & 42 & 11 & 124 \\
\hline $40-44$ & 3 & 31 & 9 & 100 \\
\hline Total & 1,069 & 1,429 & 771 & 1,097 \\
\hline
\end{tabular}

\section{FIGURE 3}

Proportion of rubella cases by birth cohort, Salaj, Romania, 1 September 2011-23 January 2012

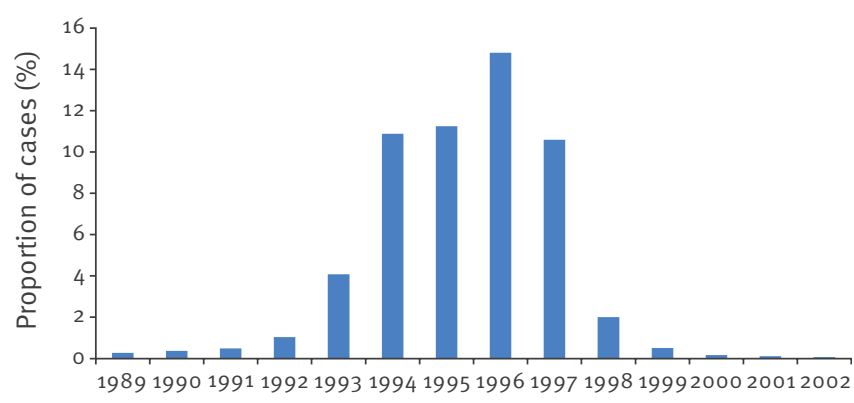

Year of birth
Salaj District during 2003 to 2008 is higher with $3.8 \%$ on average than the coverage in the whole country for the same period. For 2005 to 2009 , the MMR vaccination coverage in Salaj was below the country average, except for seven-year-old children vaccinated with MMR in 2008 and 2010 when the district coverage was higher than the country average (Figure 4).

\section{FIGURE 4}

Coverage of (A) MMR vaccination at 12-15 months (2005-2009), (B) MMR vaccination at seven years (20052010) and (C) rubella-containing vaccine in girls aged 13-14 years (2003-2008), Romania and Salaj district

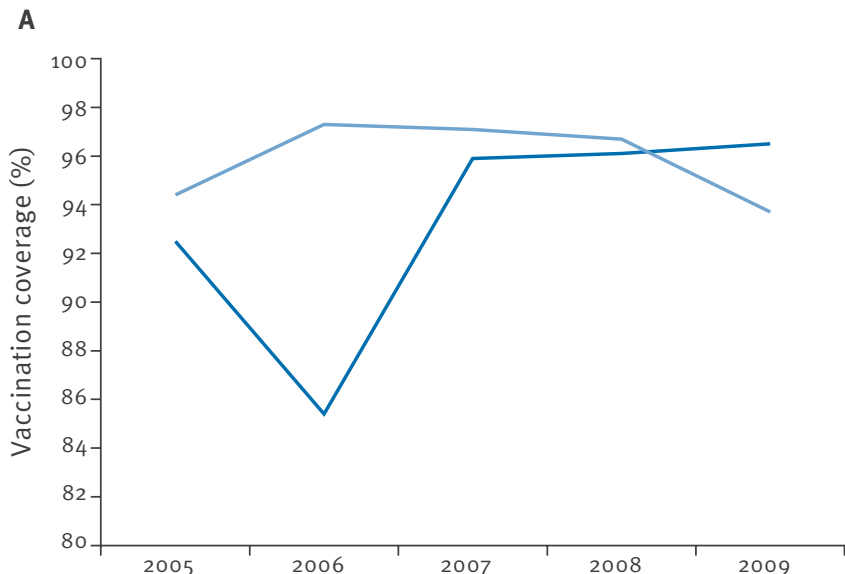

B
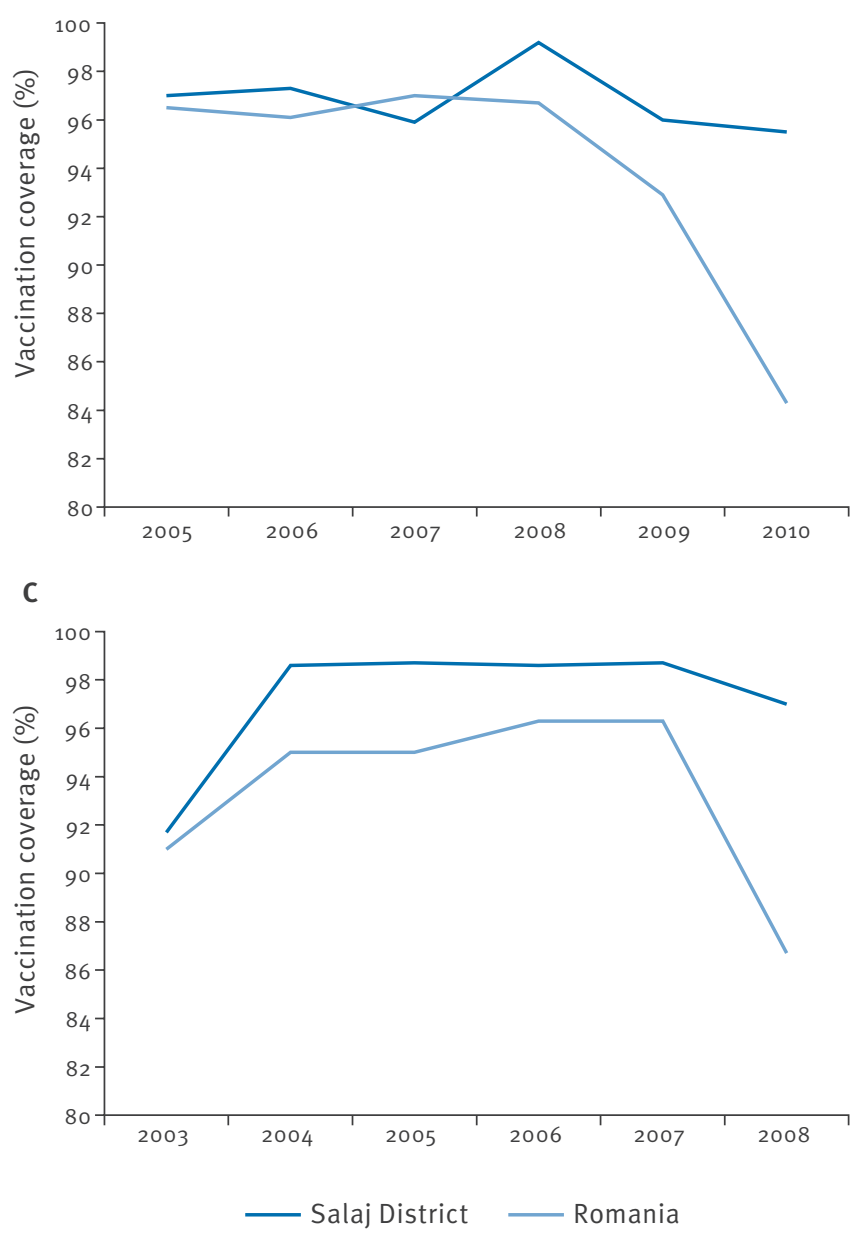


\section{Control measures}

Since the identification of the outbreak, several control measures have been implemented by the local health authorities. The most important one was the initiation of a MMR vaccination campaign in the district of Salaj targeting all children and adolescents aged between 10 and 19 years, irrespective of their vaccination status. The MMR vaccine is supplied by the Ministry of Health and is offered free of charge through routine immunisation services (family physicians) and special outreach teams. As a result of this special campaign, 210 persons were vaccinated until 31 December 2011 but many parents still refused to have their children vaccinated. Local healthcare workers (doctors and nurses) were recommended to get vaccinated and to try to inform and increase awareness among their patients on the risk of this disease, especially among women of childbearing age.

Additionally, the local public health authorities have initiated rubella screening among pregnant women epidemiologically linked to a probable or a confirmed case. While the general recommendations for MMR vaccination are maintained at national level, some districts bordering Salaj (Alba, Bihor and Cluj) - which were also affected by rubella but to a lesser extent - have issued vaccination recommendations among teenagers to avoid other potential outbreaks.

\section{Discussion and conclusions}

The results of the investigation revealed that of the total number of rubella described above, $98 \%$ had never been vaccinated against rubella infection. The index case was an unvaccinated teenager and 1,206 of the rubella cases $(65.5 \%)$ occurred among teenagers aged between 15 and 19 years (born between 1992 and 1996). Taking into account the historical MMR vaccination schedule in Romania, 770 children born between 1995 and 1996 (15-16-year-olds in 2011) were not eligible for rubella vaccination and represent $41.8 \%$ of all cases. In the birth cohort 1992-1994 only girls were eligible of rubella vaccine at the age of 14 years.

Measures such as catch up campaigns are important to close existing gaps in vaccination and prevent further spread of the outbreak. Educating the general public on modes of rubella transmission and stressing the need for rubella vaccination is the most important way to prevent further spread of the disease in other districts and to prevent congenital infection.

Although the outbreak has passed its peak and is subsiding, surveillance for rubella will be maintained for a least two incubation periods (46 days) following onset of rash of the last case [9]. Moreover, active surveillance for infants with CRS will be carried out until the age of nine months after the last reported rubella case [10].
Acknowledgments

The authors wish to thank the team of epidemiologists from Salaj district involved in the outbreak investigation, the local EPIET supervisor Dr Florin Popovici and the EPIET coordinator Alicia Barrasa.

\section{References}

1. Commission Decision of 19 March 2002 laying down case definitions for reporting communicable diseases to the Community network under Decision No 2119/98/EC of the European Parliament and of the Council. Official Journal of the European Communities. 3 Apr 2002. Available from: http://eurlex.europa.eu/LexUriServ/LexUriServ.do?uri=0J:L:2002:086:0 044:0062:EN:PDF

2. National Assembly of Romania. Legea Nr. 3 din 6 iulie 1978 privind asigurarea sanatatii populatiei cu modificarile ulterioare. [Law no 3 of 6 July 1978 regarding population health and subsequent modifications]. Official Journal no 54. 10 Jul 1978.

3. National Centre for Communicable Diseases Surveillance and Control (CNSCBT). Metodologia de supraveghere a infectiei rubeolice congenitale (inclusiv sindromul rubeolic congenital). [Methodology of surveillance for congenital rubella infection (including congenital rubella syndrome)]. CNSCB. [Accessed 26 Jan 2012]. Available from: http://www.insp.gov.ro/cnscbt/index. php?option=com_docman\&task=cat_view\&gid=50\&Itemid=10

4. World Health Organization Regional Office for Europe (WHO). Renewed commitment to measles and rubella elimination and prevention of congenital rubella syndrome in the WHO European Region by 2015. Copenhagen: WHO. 23 Jul 2010. Available from: http://www.euro.who.int/__data/assets/pdf file/0008/119546/RC60 edoc15.pdf

5. Pistol A, Hennessey K, Pitigoi D, Ion-Nedelcu N, Lupulescu E, Walls L, et al. Progress toward measles elimination in Romania after a mass vaccination campaign and implementation of enhanced measles surveillance. J Infect Dis. 2003;187 Suppl 1:S217-22.

6. Rafila A, Marin M, Pistol A, Nicolaiciuc D, Lupulescu E, Uzicanin A, et al. A large rubella outbreak, Romania - 2003. Euro Surveill. 2004;9(4):pii=457. Available from: http://www. eurosurveillance.org/ViewArticle.aspx?Articleld=457

7. National Centre for Communicable Diseases Surveillance and Control (CNSCBT). Annual report on communicable diseases 2010. CNSCBT. Accessed 15 Dec 2011. Romanian. Available from: http://www.insp.gov.ro/cnscbt/index. php?option=com_docman\&Itemid=11

8. National Centre for Communicable Diseases Surveillance and Control (CNSCBT). Annual report on communicable diseases 2009. CNSCBT. [Accessed 15 Dec 2011]. Romanian. Available from: http://www.insp.gov.ro/cnscbt/index. php?option=com docman\&Itemid $=11$

9. Centers for Disease Control and Surveillance (CDC). VPD Surveillance Manual, 4th Edition, 2008. Rubella: Chapter 14. Atlanta: CDC. [Accessed 15 Dec 2011]. Available from: http:// www.cdc.gov/vaccines/pubs/surv-manual/chpt14-rubella.pdf

10. Heymann DL (ed.). Control of Communicable Diseases Manual. 19th Edition. American Public Health Association: Washington, 2008. 